$\begin{array}{ll}\text { Makalenin Türü / Article Type } & \text { : Araştırma Makalesi / Researh Article } \\ \text { Geliş Tarihi / Date Received } & : 28.05 .2019 \\ \text { Kabul Tarihi / Date Accepted } & : 10.09 .2019 \\ \text { Yayın Tarihi / Date Published } & : 11.10 .2019\end{array}$

https://dx.doi.org/10.17240/aibuefd.2019.19.49440-571174

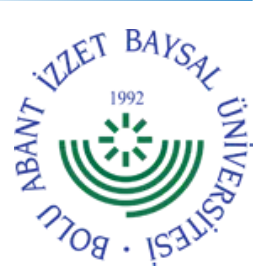

\title{
BEDEN EĞITIMİ ÖĞRETMEN ADAYLARININ MESLEKİ KAYGILARI
}

\author{
Ali AYCAN ${ }^{1}$, Hanifi ÜZÜM²
}

\section{ÖZ}

Bu çalışmanın amacı, beden eğitimi öğretmen adaylarının, öğretmenlik mesleğine ilişkin algıladıkları kaygı düzeylerinin bazı değişkenlere göre incelenmesidir. Çalışmanın örneklem grubunu, Bolu Abant İzzet Baysal Üniversitesi ve Bartın Üniversitelerinin Beden Eğitimi Öğretmenliği, Antrenörlük Eğitimi ve Spor Yöneticiliği bölümlerinde okuyan 185 erkek ve 92 kadın olmak üzere toplam 277 öğrenci oluşturmuştur. Araştırma verileri, Cabı ve Yalçınalp (2013) tarafindan geliştirilmiş "Mesleki Kaygı Ölçeği” (MKÖ) aracılığıyla toplanmıştır. Verilerin analizi için Mann Whitney U-testi ve Spearman Korelasyon testi uygulanmıştır. Araştırma sonucuna göre beden eğitimi öğretmeni adaylarının mesleki kaygıları genel olarak düşük iken, cinsiyet açısından kadınların erkeklere oranla atanma merkezli kaygılarının anlamlı düzeyde yüksek olduğu saptanmıştır. Ayrıca, öğretmen adaylarının, beden eğitimi öğretmenliği bölümü öğrencisi veya pedagojik formasyon programı ögrencisi olmaları açısından mesleki kaygı düzeylerinin farklılaşmadığı sonucuna varılmıştır.

Anahtar Kelimeler: Beden Eğitimi Öğretmen Adayları, Mesleki Kaygı

\section{OCCUPATIONAL ANXIETY of PHYSICAL EDUCATION TEACHER CANDIDATES}

\begin{abstract}
The purpose of this study was to investigate the effect of some variables on perceived occupational anxiety level of physical education teacher candidates. The sample of the study consisted of 277 physical education teacher candidates $(\mathrm{n}=185$ male and $\mathrm{n}=92$ female) from department of physical education, training education and sport management of Bolu Abant İzzet Baysal Üniversity and Bartın Üniversity. Research data were obtained by “occupational anxiety Scale" (OAS) consisting of 45 items and 8 dimensions developed by Cabı and Yalçınalp, (2013). The data were analysed by Mann Whitney U-test and Spearman Correlation tests. The results showed that physical education teacher candidates are generally low in occupational anxiety, but in terms of gender women have more appointment anxiety than men. In addition, it was concluded that the occupational anxiety level did not differed, in terms of being student of physical education teacher department or pedagogical formation program.
\end{abstract}

Keywords: Physical Education Teacher Candidates, Occupational Anxiety

1 Abant İzzet Baysal Üniversitesi, Spor Bilimleri Fakültesi, e-posta: aycan_a1@ibu.edu.tr, 대ttps://orcid.org/0000-0002-4354-2526.

$2{ }^{2}$ Abant İzzet Baysal Üniversitesi, Spor Bilimleri Fakültesi, e-posta: uzum_h@ibu.edu.tr, 느ttps://orcid.org/0000-0002-0555-266X. 


\section{GíRiş}

Bir ülkenin sahip olduğu nitelikli insan gücü, o ülkenin gelişmişlik düzeyinin de temel belirleyicisidir. Topluma katkı sağlayacak insanın yetiştirilmesi ise etkili bir eğitim ve öğretim faaliyetlerini gerekli kılmaktadır. Toplumlar, bireyleri gelişigüzel etkilere maruz bırakmadan kendilerine özgü biçimde yetiştirebilmek için, eğitim sürecinin amaçlarını ve içeriğini belirlemiş, kontrol altına almış ve bir kamu hizmeti olarak kurumlaştırmıştır (Nurettin, 1986).

Okullar, eğitim ve öğretim hizmetinin verildiği örgün eğitim kurumlarıdır. Okul sisteminin en başta gelen görevleri arasında içinde bulunduğu toplumun devamlılığını ve gelişmesini sağlamak gösterilebilir. Bütün ülkeler sürekli değiş̧en ve gelişen çağa ayak uydurabilmek ya da onu yönlendirebilmek için eğitim sistemlerinde gerekli yenilikleri yapmak durumundadır (Hergüner, 1992; Akınoğlu, 2005). Eğitim faaliyetlerinin başarısında okul, öğretmen, öğrenci ve eğitim programları hayati öneme sahip olmasına rağmen, kuşkusuz bu yapının en önemli öznesi öğretmendir (Özkan, 2012; Çelikten vd., 2005; Seferoğlu, 2004).

Öğretmenlik aynı anda birçok farklı toplumsal rolün yerine getirilmesi zorunluluğunu gerektiren karmaşık bir meslektir (Oktay, 1991). Bunun yanında, evrensel ve yerel kültürel mirasın yeni nesillere aktarılmasına, bireylerin tüm yeteneklerinin ortaya çıkarılmasına ve yeni bilgi ve becerilerin kazandırılmasına yönelik uğraşları nedeniyle öğretmenlik, bütün toplumlarda diğer mesleklerden daha farklı bir yere sahiptir. Öğretmenlik oldukça özveri gerektiren kutsal bir meslek olarak görülmektedir (Güven, 2010).

Geleceğin inşasında kilit role sahip bir uzmanlık alanı olan öğretmenlik mesleği, beraberinde çok yönlü gelişmeyi ve birçok konuda yeterlilik sahibi olmayı da zorunda kılmaktadır. Öğretmenin bu rolünü etkin bir şekilde yerine getirebilmesi öncelikle alanında iyi yetiştirilmesine ve kendisini işine tam anlamıyla vermesine olanak sağlayacak uygun koşulların oluşturulmasına bağlı olduğu söylenebilir (Özkan, 2012). Sürekli değişim ve gelişim içinde olan dünyanın ihtiyaçlarına cevap verecek nitelikte öğretmenlere sahip olabilmek için, öğretmen adaylarının yetiştirilmesindeki eksikliklerin iyi analiz edilmesi ve mevcut öğretmenlerin ise hizmet içi eğitimler ile yeni duruma adapte edilmesi gerekmektedir. Bu durumun oldukça karmaşık, çok boyutlu ve süreklilik arz eden bir çaba gerektirdiği söylenebilir.

Öğretmenlerin yetiştirilmesi sürecinde karşılaşılan ve bu sürecin kalitesi üzerinde oldukça etkili olan başlıklardan biri de öğretmen adaylarının mesleğe yönelik algıladıkları kaygılardır. Öğretmenlik mesleğine yönelik duyulan kaygılar, hiç kuşkusuz bu mesleğe hazırlanan adayların eğitim süreçlerini ve motivasyonlarını olumsuz yönde etkileyecektir. Öğretmen adaylarının öğretmenlik mesleğine yönelik kaygılarının belirlenmesi amacıyla Cabı ve Yalçınalp, (2013) in yapmış olduğu bir çalışmada, "Görev", "Ekonomik/Sosyal”, "Öğrenci / İletişim", "Meslektaş ve Veli", "Kişisel Gelişim", "Atanma", "Uyum", ve "Okul Yönetimi” ile ilgili konular ile bağlantılı öğretmen adaylarının kaygı duydukları tespit edilmiştir.

\subsection{Araştırmanın Amacı}

$\mathrm{Bu}$ çalışmada, beden eğitimi öğretmeni adaylarının, öğretmenlik mesleğine ilişkin sahip oldukları kaygı düzeylerinin bazı değişkenlere göre ne yönde farklılaştığının belirlenmesi amaçlanmıştır.

\subsection{Araştırmanın Önemi}

Bu çalışma, spor bilimleri alanında öğrenim gören beden eğitimi öğretmeni adaylarının öğretmenlik mesleğine yönelik kaygıların giderilmesi veya azaltılması yönünde bazı önerilerin sunulması ve alan yazına katkı sağlaması bakımından önemlidir.

\section{YÖNTEM}

\subsection{Araștırmanın Modeli}

$\mathrm{Bu}$ çalışma, genel tarama modellerinden birisi olan kesit alma yöntemi ve ilişkisel tarama yöntemi doğrultusunda yapılmıştır.

\section{2. Çalışma gurubu}

Araştırmanın çalışma evreni aynı zamanda örneklem grubunu oluşturmuştur. Çalışmanın amacına göre oransız küme örnekleme yöntemi ile seçilen örneklem grubu, Bolu Abant İzzet Baysal Üniversitesi ve Bartın Üniversitesinin Beden Eğitimi ve Spor Yüksekokulunun Öğretmenlik, Antrenörlük ve Spor Yöneticiliği bölümlerinde okuyan 185 erkek ve 92 kadın olmak üzere toplam 277 öğrenciden oluşmuştur. 


\subsection{Veri Toplama aracı}

Çalışmada veri toplama aracı olarak dört sorudan oluşan ve demografik özellikler ile ilgili araştırmacı tarafından oluşturulan kişisel bilgi formunun ile Cabı ve Yalçınalp (2013) tarafından geliştirilen "Mesleki Kaygı Ölçeği” (MKÖ) kullanılmıştır. 45 soru ve 8 alt boyuttan oluşan ölçeğin Alfa iç tutarlılık değerleri bu çalışma için, "Görev Merkezli Kayg1 boyutu, $\alpha=0.93$ ", "Ekonomik/Sosyal Merkezli Kayg1 boyutu, $\alpha=0.80$ ”, "Öğrenci/İletişim Merkezli Kaygı boyutu, $\alpha=0.87$ ", "Meslektaş ve Veli Merkezli Kaygı boyutu, $\alpha=0.60$ ”, "Kişisel Gelişim Merkezli Kayg1 boyutu, $\alpha=0.86$ ", “Atanma Merkezli Kaygı boyutu, $\alpha=0.56$ ", "Uyum Merkezli Kaygı boyutu, $\alpha=0.68$ ”, ve Okul Yönetimi Merkezli Kaygı boyutu, $\alpha=0.70$ olarak tespit edilmiştir. Toplam ölçeğin Cronbach Alpha iç tutarlılık değerleri ise $\boldsymbol{\alpha}=\mathbf{0 . 9 4}$ olarak bulunmuştur. Ölçek 5'li likert formatında (1=Çok Kaygılanıyorum, 2=Oldukça Kaygılanıyorum, 3=Kısmen Kaygılanıyorum, 4=Çok Az Kaygılanıyorum, 5=Kaygılanmıyorum) derecelendirilmiştir (Cabı ve Yalçınalp, 2013).

Bu çalışmada katılımcılara yüz yüze görüşme yöntemi ile yaklaşık 350 adet anket formu dağıtılmıştır. Dağıtılan bu formların 300 tanesi geri dönmüş ve doğru olarak doldurulduğu kabul edilen 277 form değerlendirmeye alınmıştır.

\subsection{Verilerin analizi}

Elde edilen verilerin analizi için öncelikli olarak gruplara Kurtosis ve Skewness gibi normallik testi uygulanmış ve grupların normal dağılım göstermediği tespit edilmiştir $\mathrm{P}<0,05$. Bu nedenle non-parametrik hipotez testlerinin kullanılmasına karar verilmiştir. Bu doğrultuda katılımcıların demografik verilerinin dağılımının belirlenmesi için yüzde (\%) ve frekans (f) analizleri, iki grubun karşılaştırılması için Mann Whitney U-testi, gruplandırılmayan sürekli sayısal veriler için Spearman Korelasyon testleri uygulanmıştır. Çalışmanın anlamlılık düzeyi $\mathrm{p}<0,05$ olarak kabul edilmiştir.

\section{BULGULAR}

Yapılan analizler sonucunda katılımcıların demografik özellikleri ile ilgili bulgular Tablo 1'de verilmiştir.

Tablo 1.

Katılımcıların Demografik Özellikleri

\begin{tabular}{llccc}
\hline & & Sayı & \% & Toplam \\
\hline Cinsiyet & Kadın & 92 & 33,2 & \\
& Erkek & 185 & 66,8 & 277 \\
Bölüm & Öğretmenlik & 191 & 69,0 & \\
& Spor Yöneticiliği & 53 & 19,1 & 277 \\
& Antrenörlük & 33 & 11,9 & \\
Sınıf & 1.Sinıf & 126 & 45,5 & \\
& 2.Sinıf & 41 & 14,8 & \\
& 3.Sinıf & 42 & 15,2 & 277 \\
\hline
\end{tabular}

Katılımcıları "Mesleki Kaygı Ölçeği”" alt boyutlarına verdikleri cevapların aritmetik ortalama ve standart sapmaları Tablo 2'de verilmiştir.

\section{Tablo 2.}

Alt Boyutların Aritmetik Ortalamaları Ve Standart Sapmaları

\begin{tabular}{lcc}
\hline Alt Boyutlar & Aritmetik Ortalama & Standart Sapma \\
\hline Görev Merkezli Kaygı & 1,98 & 0,74 \\
Ekonomik/Sosyal Merkezli Kaygı & 2,57 & 0,85 \\
Öğrenci/İletişim Merkezli Kaygı & 1,99 & 0,87 \\
Meslektaş ve Veli Merkezli Kaygı & 1,97 & 0,98 \\
Kişisel Gelişim Merkezli Kaygı & 1,88 & 0,89 \\
Atanma Merkezli Kaygı & 3,10 & 1,40 \\
Uyum Merkezli Kaygı & 2,20 & 0,91 \\
Okul Yönetimi Merkezli Kaygı & 2,57 & 0,94 \\
\hline
\end{tabular}

Tablo 2 incelendiğinde, Katılımcıların algıladıkları en yüksek mesleki kaygının atanma merkezli $(\bar{x}=3,10 \pm 1,40)$ ve en düşük kaygının ise kişisel gelişim merkezli $(\bar{x}=1,88 \pm 0,89)$ olduğu görülmektedir. 
Tablo 3.

Cinsiyete Göre Alt Boyutların Karşılaştırılması

\begin{tabular}{llccccc}
\hline & Cinsiyet & $\boldsymbol{n}$ & $\boldsymbol{S . O}$ & $\boldsymbol{S . T}$ & $\boldsymbol{U}$ & $P$ \\
\hline Atanma Merkezli & Erkek & 185 & 128,22 & 23721,50 & 6516,500 & 0,01 \\
Kaygı & Kadın & 92 & 160,67 & 14781,50 & & \\
\hline $\boldsymbol{*} \mathbf{P}<\mathbf{0 , 0 5}$ & & & & &
\end{tabular}

Tablo 3 incelendiğinde, cinsiyet ile atanma merkezli kaygı alt boyutu arasında $\mathrm{p}<0.05$ düzeyinde anlamlı fark bulunmuştur. Sıra ortalamaları incelendiğinde kadınların ortalamasının erkeklerden daha yüksek olduğu görülmektedir. Cinsiyete göre kaygının diğer alt boyutları arasında anlamlı farklılık bulunmamıştır.

Tablo 4.

Bölüm Değişkenine Göre Alt Boyutların Karşılaştırılması

\begin{tabular}{|c|c|c|c|c|c|c|}
\hline & Bölüm & $\mathbf{n}$ & S.O & S.T & $\mathbf{U}$ & $\mathbf{P}$ \\
\hline \multirow[t]{2}{*}{ Görev Merkezli Kaygı } & Öğretmenlik Bölümü & 191 & 138,37 & 26429,50 & 8093,500 & ,84 \\
\hline & Formasyon Alan & 86 & 140,39 & 12073,50 & & \\
\hline \multicolumn{2}{|c|}{ Ekonomik/Sosyal Merkezli Kaygı Öğretmenlik Bölümü } & 191 & 140,76 & 26886,00 & 7876,000 &, 58 \\
\hline & Formasyon Alan & 86 & 135,08 & 11617,00 & & \\
\hline \multirow[t]{2}{*}{ Öğrenci/İletişim Merkezli Kaygı } & Öğretmenlik Bölümü & 191 & 140,68 & 26869,50 & 7892,000 & 60 \\
\hline & Formasyon Alan & 86 & 135,27 & 11633,50 & & \\
\hline \multirow[t]{2}{*}{ Meslektaş ve Veli Merkezli Kaygı } & IÖğretmenlik Bölümü & 191 & 137,42 & 26248,00 & 7912,000 & ,62 \\
\hline & Formasyon Alan & 86 & 142,50 & 12255,00 & & \\
\hline \multirow[t]{2}{*}{ Kişisel Gelişim Merkezli Kaygı } & Öğretmenlik Bölümü & 191 & 138,78 & 26507,00 & 8171,000 & ,94 \\
\hline & Formasyon Alan & 86 & 139,49 & 11996,00 & & \\
\hline \multirow[t]{2}{*}{ Atanma Merkezli Kaygı } & Öğretmenlik Bölümü & 191 & 138,07 & 26371,50 & 8035,500 & ,77 \\
\hline & Formasyon Alan & 86 & 141,06 & 12131,50 & & \\
\hline \multirow[t]{2}{*}{ Uyum Merkezli Kaygı } & Öğretmenlik Bölümü & 191 & 139,14 & 26575,00 & 8187,000 & 96 \\
\hline & Formasyon Alan & 86 & 138,70 & 11928,00 & & \\
\hline \multirow[t]{2}{*}{ Okul Yönetimi Merkezli Kaygı } & Öğretmenlik Bölümü & 191 & 137,37 & 26237,50 & 7901,500 & ,61 \\
\hline & Formasyon Alan & 86 & 142,62 & 12265,50 & & \\
\hline
\end{tabular}

$\mathbf{P}>\mathbf{0 , 0 5}$

Tablo 4 incelendiğinde, bölüm değişkenine göre öğretmenlik bölümü öğrencileri ile formasyon alan (Antrenörlük eğitimi, spor yöneticiliği) öğrenciler arasında Kaygı alt boyutları arasında yapılan İlişkisiz ölçümler (Mann Whitney-U) testi sonucunda anlamlı fark tespit edilmemiştir $\mathrm{P}>0,05$.

Katılımcıların öğrenim gördükleri sınıf değişkeni ile Mesleki Kaygı Ölçeği alt boyutları arasında istatistiksel olarak anlamlı fark bir fark tespit edilmemiştir $\mathrm{P}>0,05$. Yine katılımcıların akademik ortalamaları ile Mesleki kayg1 ölçeğinin alt boyutları arasında istatistiksel olarak anlamlı bir ilişki bulunmamaktadır $\mathrm{P}>0,05$.

\section{TARTIŞMA ve SONUÇ}

Beden eğitimi öğretmen adaylarının, öğretmenlik mesleğine ilişkin sahip oldukları kaygı düzeylerinin bazı değişkenlere göre incelenmesinin amaçlandığı bu çalışmada, katılımcıların algıladıkları mesleki kaygı düzeyleri diğer bütün boyutlarda düşük olasına rağmen, en yüksek mesleki kaygının atanma merkezli kaygı (tablo 2) boyutunda olduğu belirlenmiştir. Atanma merkezli kaygı boyutunun daha çok KPSS (Kamu Personel Seçme Sınav1) ile ilgili olduğu söylenebilir. KPSS öğretmenlik yapma yeterliliğine sahip bireylerin öğretmenlik kadrosuna atanıp atanamayacağını belirleyen bir seçme sınavıdır. Belirli sayıda öğretmen atamasının yapılıyor olması ve devletin kadrolu öğretmeni olmanın artıları, öğretmen adayları açısından bu sınavı oldukça önemli kılmaktadır. Bu durum, atanma merkezli kaygı boyutunun yüksek algılanmasına neden olmuş olabilir. Gökmen ve Ekici (2018), öğretmen adaylarının özellikle atanma merkezli kaygılarının yüksek olduğu ve ilgili kurumların bu durumu azaltacak uygun çalışmalar içinde olmaları gerektiğini belirtmişlerdir. Çelen ve Bulut (2015) ise, öğretmen adaylarının atanma merkezli kaygıyı daha fazla yaşadıklarını ve mezun olduktan sonra girecekleri KPSS'nın bu kaygının en önemli nedeni olabileceğini saptamışlardır.

Bunun yanında, katılımcıların düşük mesleki kaygı düzeyine sahip olmaları ve farklı programlarda öğrenci olmaları bakımından mesleki kaygılarının farklılaşmaması, katılımcıların öğretmenlik mesleğine yönelik yüksek öz yeterlilik inancına sahip olmalarından kaynaklanıyor olabilir. Bandura ( 1997) öz yeterliliği, bireyin belli bir davranışı gerçekleştirmesi için gerekli olan eylemleri düzenleme ve uygulayabilme kapasitesine duyduğu inanç olarak tanımlamaktadır. Bu bağlamda öğretmenlik mesleği öz yeterliliğini, öğretmenlik görev ve sorumluluklarını yerine getirme kapasitesine yönelik duyulan inanç olarak tanımlayabiliriz. Öğretmen adayları ile yapılan bazı çalışmalarda, öğretmen adaylarının öz yeterlik inancı yükseldikçe mesleki kaygı düzeylerinin azaldığı ve öz yeterliliğin mesleki kaygının anlamlı bir yordayıcısı olduğu sonucuna varılmıştır (Ünlü ve Erbaş 2018; Kahraman ve Çelik 2019; Dadandı vd.. 2016; Gökmen ve Ekici, 2018). Genel anlamda, yüksek mesleki öz yeterlilik algısına 
sahip bireylerin, mesleki kaygılarının düşük olabileceği sonucuna varılabilir. Varol vd (2014) yapmış oldukları çalışmada, öğretmen adaylarının mesleki kaygı düzeylerin düşük olduğunu ve algıladıkları kaygının ise mesleğe yönelik olumlu ve geliştirici bir uyaran olarak düşünülebileceğini belirtmişlerdir.

Araştırmanın bir diğer bulgusu ise, katılımcıların cinsiyetleri açısından algıladıkları mesleki kaygı düzeylerinin istatistiksel olarak anlamlı düzeyde farklılaştığı yönündedir (Tablo 3). Bu bulguya göre, kadın beden eğitimi öğretmeni adayları erkek adaylardan anlamlı düzeyde yüksek atanma merkezli kaygıya sahiptir (Tablo 3). Başka bir ifadeyle, öğretmen adayları en fazla atanma merkezli kaygı yaşarken, kadın adayların söz konusu kaygıyı erkeklere oranla anlamlı düzeyde daha fazla yaşadıklarıdır. Atanma merkezli kaygı boyutunda kadın öğretmen adaylarının anlamlı düzeyde erkeklerden yüksek kaygı duymalarına ise, toplumsal cinsiyet rolleri açısından bakılabilir. Toplumumuzda, öğretmenliğin özellikle kadınlar için uygun bir meslek olduğu hem aile hem de iş hayatlını birlikte yürütülebilmesine olanak sağladığı ve devlet memuru olmanın önemli olduğu yönündeki düşüncelerin hakim olduğu söylenebilir. Bu toplumsal düşünce, kadınlar için öğretmenlik mesleğini erkeklere oranla çok daha elde edilmesi gereken bir konuma sokmuş olabilir. KPSS sınavının öğretmen olarak atanma önündeki en önemli engellerin başında gelmesi, kadınların bu boyutta erkeklere göre daha fazla kaygı duymalarının nedeni olabilir. Varol vd. (2014) yapmış oldukları çalışmada, kadın ve erkek öğretmen adaylarının algıladıkları toplam kaygı puanları arasında anlamlı bir fark olmamasına rağmen, atanma merkezli kaygı boyutunda kadın adaylar erkek adaylara göre anlamlı düzeyde kaygı yaşadıkları tespit edilmiştir.

Ayrıca, araştırmaya katılan öğretmen adaylarının algıladıkları mesleki kaygı düzeyleri, beden eğitimi öğretmenliği bölümü öğrencisi veya pedagojik formasyon programı öğrencisi olmaları bakımından istatistiksel olarak anlamlı bir farklılık göstermemektedir (Tablo 4). Beden eğitimi öğretmenliği, spor yöneticiliği ve antrenörlük eğitimi bölümlerinin programları birbirinden farklılık gösterse de, bir öğrenci en az altı veya 7 sportif uygulama dersi alarak mezun olmaktadır. Bu öğrencilerin sportif öz geçmişlerinin birbirine benzer olması, çoğunlukla ilk tercihlerinin öğretmenlik bölümünden yana olması ve aynı ortamda yakın ilişkiler içinde bulunmalarıyla oldukça ortak yönlere sahip oldukları söylenebilir. Beden eğitimi öğretmenliğinin sportif uygulamaya dönük bir meslek olduğu da göz önüne alındığında, spor ile ilişkileri bakımından benzer özellikler gösteren öğrencilerin konuya ilişkin algılarının da benzer olması oldukça makul görülmektedir. Temel vd. (2016) pedagojik formasyon eğitimi alan spor yöneticiliği ve antrenörlük eğitimi bölümü öğrencileri gerçekleştirmiş oldukları çalışmada, katılımcıların öncelikle devlette istihdam firsatı olarak değerlendirdikleri beden eğitimi öğretmenliğini hayallerindeki meslek olarak gördüklerini ve beden eğitimi öğretmenliğine ilişkin yeterli bilgi ve donanıma sahip olduklarını düşüncesini taşıdıklarını belirtmişlerdir.

Sonuç olarak, beden eğitimi öğretmeni adaylarının mesleki kaygıları genel olarak düşük olsa da özellikle kadınların erkeklere oranla atanma merkezli kaygılarının anlamlı düzeyde yüksek olduğu saptanmıştır. Son olarak, öğretmen adaylarının beden eğitimi öğretmenliği öğrencisi veya pedagojik formasyon programı öğrencisi olmaları açısından mesleki kaygı düzeylerinin farklılaşmadığı sonucuna varılmıştır.

Araştırmanın daha geniş bir örneklem grubu ile çalışılması, öğretmen adaylarının öğretmenlik staj uygulaması öncesi ve sonrası mesleki kaygılarının araştırılmasının, konunun daha detaylı anlaşılmasına katkı sağlayabileceği düşünülmektedir. 


\section{KAYNAKÇA}

Akınoğlu, O. (2005). Türkiye'de uygulanan ve değişen eğitim programlarının psikolojik temelleri. Atatürk Eğitim Fakültesi Eğitim Bilimleri Dergisi, 22, 31-46.

Bandura, A. (1997). Theoretical perspectives. Self-efficacy: The exercise of control, 1-35.

Cabı, E., \& Yalçınalp, S. (2013). Öğretmen adaylarına yönelik mesleki kaygı ölçeği (MKÖ): geçerlik ve güvenirlik çalışması. Hacettepe Üniversitesi Eğitim Fakültesi Dergisi, 44(44), 85-96.

Çelen A. \& Bulut D. (2015) Beden eğitimi öğretmen adaylarının mesleğe yönelik kaygılarının belirlenmesi (AİBÜ Örneği), Akademik Sosyal Araştırmalar Dergisi, 3(18), 247-261

Çelikten, M., Şanal, M. \&Yeni, Y., (2005). Öğretmenlik mesleği ve özellikleri. Erciyes Üniversitesi Sosyal Bilimler Enstitüsü Dergisi, 1(19), 207-237.

Dadandı İ., Kalyon A., Yazıcı H. (2016). Eğitim fakültesinde öğrenim gören ve pedagojik formasyon eğitimi alan öğretmen adaylarının öz-yeterlik inançları, kaygı düzeyleri ve öğretmenlik mesleğine karşı tutumları. Bayburt Eğitim Fakültesi Dergisi, 11(1), 253-269.

Fidan, N. (1986). Okulda öğrenme ve ögretme. Gül Yayınevi.

Gökmen, A. \& Ekici, G. (2018). Biyoloji öğretmen adaylarının öğretmen öz-yeterlik algı düzeyleri ile mesleki kaygıları arasındaki ilişkinin incelenmesi, Anadolu Ögretmen Dergisi, 2(2), 17-28.

Güven, D. (2010). Profesyonel bir meslek olarak Türkiye'de öğretmenlik. Boğaziçi Üniversitesi Eğitim Dergisi, 27(2), 13-21.

Hergüner, G. (1992). Eğitim - Spor İlişkisi, On Dokuz Mayıs Üniversitesi Eğitim Fakültesi Dergisi, 7, 61.

http://www.mevzuat.gov.tr/MevzuatMetin/1.5.1739.pdf MILLLİ EĞITIM TEMEL KANUNU (1) Kanun Numaras1 : 1739 Kabul Tarihi : 14/6/1973 Yayımlandığı R.Gazete : Tarih : 24/6/1973 Sayı : 14574 Yayımlandığı Düstur : Tertip : 5 Cilt : 12 Sayfa : 2342.

Kahraman, Ü., \& Çelik, K. (2019) Eğitim fakültesi formasyon öğrencilerinin özyeterlik inançları ile mesleki kaygıları arasındaki ilişki. Pamukkale Üniversitesi Ë̆itim Fakültesi Dergisi, 45(45), 353-375.

Kalemoğlu, V. Y., Erbaş, M. K., \& Ünlü, H., (2014). Beden eğitimi öğretmen adaylarının mesleki kaygı düzeylerinin öğretmenlik mesleğine yönelik tutumların yordama gücü. SPORMETRE Beden Eğitimi ve Spor Bilimleri Dergisi, 12(2), 113-123.

Oktay, A. (1991). Öğretmenlik mesleği ve öğretmenin nitelikleri. M.Ü. Atatürk eğitim fakültesi Eğitim Bilimleri Dergisi, 3, 187-198

Özkan, H. H. (2012). Öğretmenlik formasyon programındaki öğretmen adaylarının öğretmenlik mesleğine ilişkin tutumlarının incelenmesi (SDÜ Örneği). Ahi Evran Üniversitesi Kırşehir Eğitim Fakültesi Dergisi, 13(2), 29-48.

Seferoğlu, S. S. (2004). Öğretmen yeterlilikleri ve mesleki gelişim. Bilim ve Aklın Aydınlı̆̆ında Eğitim, 58, 40-45.

Temel, C., Altınkök, M., \& Kayışoğlu, N. B. (2016). Pedagojik formasyon eğitimi uygulamasının beden eğitimi öğretmenliğine yansımaları. International Journal of Human Sciences, 13(1), 1862-1872. doi:10.14687/ijhs.v13i1.3715

Ünlü, H., \& Erbaş, M. K., (2018). Beden Eğitimi Öğretmen Adaylarının Akademik Öz-Yeterlikleri ve Mesleki Kaygıları. Türkiye Spor Bilimleri Dergisi, 2(1), 15-25. 


\section{EXTENDED ABSTRACT}

\section{Introduction}

Qualified work force of a country is also the key determinant of that country's developement level. Societies have determined the objectives and the context of education process, taken it under control and institutionalised as a public service to educate individuals in an idiocratical way without exposing them to excursive influences (Nurettin, 1986). Schools are formal education foundations where education and training services are given. To ensure the continuance and the progress of the community that they are in can be intruduced as one of the primary duties of a school system. Every country have to implement necessary innovations to their educational system to be able to keep up with or to steer the ever-changing and ever-groving times (Hergüner, 1992; Akınoğlu, 2005).

Although the school, teacher, student and curriculum are vital for the success of educational activities, without a doubt the most important subject of this structure is the teacher (Özkan; Çelikten et al., 2005; Seferoğlu,2004). Besides that, teachership has a different place than other professions in all socities for the reason of striving towards transferring universal and local cultural heritages to new generations, discovering all the talents of individuals and help them gain new knowledge and skills. The profession of teaching which is an area of expertise that has a key role of building the future, also mandates versatile development and to have competence in a lot of subjects. It is necessary to better analyse the deficiencies of raising the teacher candidates and to adapt the existing teachers to the new situation with on-the-job trainings for the purpose of having teachers who are qualified to respond to the needs of ever-changing and ever-growing world. It can be said that this requires a quite complex, multidimensional and continuous effort.

One of the titles which is faced during the process of educating the teachers and quite effective on the quality of mentioned process is the anxiety that the candidate teachers perceive towards the profession. In a study conducted by Cab1 and Yalçınalp (2013) with the aim of identifying the teacher candidates' concerns regarding the profession of teaching; it was stated that the teacher candidates worry regarding the subjects about "Duty" , "Economical/Social”, "Student/Communication”, “Collegue and Parents”, “Self Improvement”, “Assignment”, "Concordance" and "School Management".

Hence, in this study, it was targeted to determine in which direction the physical education teacher candidates' anxiety levels related with the profession of teaching differentiate according to some variables. Thus, developing suggestions towards elimination or reducement of these teaching profession related concerns of physical education teacher candidates who are studying in the field of sports sciences constitute the importance of this study.

\section{Method}

The study was conducted in complience with cross-sectional approach of the general survey models and relational screening model. Population of the research also constituted the sample group. 185 male and 92 female students who are studying in the departments of Teaching, Coaching and Sports Management in the Schools of Physical Education and Sports of Bolu Abant İzzet Baysal University and Bartın University have formed the sample group which was selected by disproportional cluster sampling method with regard to the purpose of the study.

As data collection tool, "Occupational Anxiety Scale" which was developed by Cabı and Yalcinalp (2013) was employed in this study. Alpha internal consistency coefficients of the scale which consists of 45 items and 8 subdimensions were noted in this research as "Duty - Based Anxiety factor, $\alpha=0.93$ ", "Economical/Social Based Anxiety factor, $\alpha=0.80$ ", "Student/Communication Based Anxiety factor, $\alpha=0.87$ ", "Collegue and Parent Based Anxiety factor, $\alpha=0.60$ ", "Self - Improvement Based Anxiety factor, $\alpha=0.86$ ", "Assignment Based Anxiety factor, $\alpha=0.56$ ", "Concordance Based Anxiety factor, $\alpha=0.68$ ", and "School Management Based Anxiety factor, $\alpha=0.70$ ". Cronbach Alpha internal consistency value of the total scale was found as $\alpha=0.94$. The scale was graded in the form of 5 point likert scale (1=Very Anxious, 2=Considerably Anxious, 3=Somewhat Anxious, 4=Slightly Anxious , 5=Not Anxious).

\section{Findings, Discussion and Results}

In this research where it was aimed to investigate the physical education teacher candidates' anxiety levels that are related to the occupation of teaching with regard to some variables, it was found that the highest accoupational anxiety level is assignment - based anxiety (Table .....) even though occupational anxiety levels that the participants perceive are low in all of the other factors. I can be said that the assignment - based anxiety level is mostly related to KPSS (Public Personnel Selection Examination). KPSS is a selection examination where it was determined whether individuals who have the qualifications for teaching can be assigned to teaching positions or not. For teacher appoinments to be in a limited number and the pros of being a teacher in the state staff make this 
exam quite important from the point of candidate teachers. This situation may have caused the assignment - based anxiety to be perceived higher. Çelen and Bulut (2015) confirmed that the candidate teachers experience the assignment - based anxiety more and the most important reason for this anxiety might be the KPSS that they have to take after the graduation.

Besides that, the reason for partcipants to have low occupational anxiety levels and for occupational anxieties not to differentiate even they are students of different programmes might be the participants' high self - sufficiency belief towards the profession of teaching. In this context, we can define occupational self - sufficiancy of teaching as the belief towards the capacity of realising the duties and responsibilities of teaching. In general terms, it can be concluded that individuals with high occupational self - sufficiancy perception might have low occupational anxiety. In their study, Varol et al. (2014) indicated that occupational anxiety levels of teacher candidates are low and the anxiety they feel can be thought as a positive and constructive stimulus directed at the occupation.

Also, perceived occupational anxiety levels of candidate teachers are not significantly different in point of being a student of physical education teacher or being a student of pedagogical formation programme (Table 2). It can be said that these students have a lot in common by having similar sportive backgrounds, by mostly having teaching programmes as their first choise and by being in the same environments with closer relations. Temel et al. (2016) stated in their study on students of education of sports management and coaching department who study pedagogical formations that participants think of occupation of physical education teaching which first of all they see as an opportunity of employment in the state as thier dream job and that they think they have enough knowledge and equipment with regard to being a physical education teacher.

Another finding of the study is that female candidate physical education teachers have significantly higher assignment - based anxiety than males in accordance with the genders of the participants (Table 3). In another words, while candidate teachers mostly have assignment - based anxiety, female candidates experince the mentioned anxiety significantly more compared to the males. It can be said that, the ideas towards teaching as an occupation suitable especially for females, for teaching to enable women to run both career and family together and the pros of being a state official dominate our society. This social opinion might put occupation of teaching in a position of being more important to acquire for women rather than man. In their study, Varol et al. (2014) determined that females experience anxiety significantly more than males on assignment - based anxiety factor even though there aren't any significant difference between the total perceived anxiety scores of male and female candidate teachers.

In conclusion, for the most important element that forms the occupational anxiety of physical education teacher candidate originating from assignment - based anxiety factor is a sign of how difficult a step KPSS is to candidate teachers. 